(98.1\%) was calculated, suggesting that the Cytoclone A + B kit would make a useful screening test.

To our knowledge the CD-TOX kit has not been evaluated before. Although the figures for specificity and PPV were not as high as those for the other two kits, the high NPV (96.0\%) would also make the CD-TOX a good screening test.

Procedures for using the Premier and the CD-TOX kits were similar. With the Premier kit, results were available in about two hours 15 minutes, while with the CD-TOX, results take only about one hour 15 minutes. The Cytoclone kit was slightly more time consuming involving a centrifugation step and also more wash steps than the other kits, and results were not available for about three hours.

Both the Premier and the Cytoclone kits cost about $\$ 9.40$ (roughly $£ 4.60$ ) per specimen while the CD-TOX kit cost is about $\$ 6.25$ (roughly $£ 3.00$ ) per specimen. These costs do not allow for controls and it should be noted that each batch of specimens must have at least one positive and one negative control. The CD-TOX kit actually recommends the use of four controls with each batch, thus increasing the relative cost per specimen. It is difficult to estimate costs of tissue culture techniques as there are many hidden factors requiring consideration. The laboratory must also have appropriate facilities to maintain the cell lines and have staff familiar with these techniques.

In conclusion, small laboratories without facilities for tissue culture should find the EIA kits an excellent alternative, with all three kits performing well. An automatic plate washer and reader would further enhance the efficiency of these techniques. The CD-TOX kit is the least expensive, but if the recommendations of the manufacturer are followed, and four controls per batch are used, the cost per specimen is substantially increased. The Cytoclone kit gave the most impressive performance indices, but the test takes slightly longer to complete. All kits can be recommended and it must be left to individual laboratories to decide whether tissue culture methods or EIA kits meet the logistic needs or financial requirements of their laboratory.

1 Lyerly DM, Krivan HC, Wilkins TD. Clostridium difficile: its disease and toxins. Clin Microbiol Rev 1988;1:1-18.

2 Knoop FC, Ownes MA, Crocker IC. Clostridium difficile: Clinical disease and diagnosis. Clin Microbiol Rev 1993; 6:251-65.

3 Borriello SP, Vale T, Brazier JS, Hyde S, Chippick E. Evaluation of a commercial kit for the detection of Clostridium difficile toxin A. Eur $f$ Clin Microbiol Infect Dis Clostridium difficile

4 Delmee M, Mackey T, Hamitou A. Evaluation of a new commercial Clostridium difficile toxin A enzyme immunoassay using diarhoeal stools. Eur $\mathcal{f}$ Clin Microbiol Infect Dis 1992;11:246-9.

5 Doern GV, Coughlin RT, Wu L. Laboratory diagnosis of Clostridium difficile-associated gastrointestinal disease: comparison of a monoclonal antibody enzyme immunocor for toxins A and B with a monoclonal antibody a monocional antibody city assays. 7 Clin Microbiol 1992;30:2042-6.

city assays. F Clin Microbiol 1992;30:2042-6.
De Girolami PC, Hanff PA, Eichelberger K, Longhi L, Teresa H, Pratt J, et al. Multicenter evaluation of a new Teresa $\mathrm{H}$, Pratt J, et al. Multicenter evaluation of a new enzyme immunoassay for detection of Clostridium

7 Bowman RA, Riley TV. The laboratory diagnosis of $C$ dif ficile-associated diarrhoea. Eur $\mathcal{f}$ Clin Microbiol Infect Dis 1988;7:476-84.

8 Di Persio JR, Varga FJ, Conwell DL, Kraft JA, Kozak KJ, Willis DH. Development of a rapid enzyme immunoassay for Clostridium difficile toxin $\mathrm{A}$ and its use in the diaonosis of $C$ difficile-associated disease. $\mathcal{F}$ Clin Microbiol 1991;29. 2724-30.

\title{
Imerslund-Grasbeck syndrome in a Chinese family with distinct skin lesions refractory to vitamin $B_{12}$
}

\author{
S-H Lin, N A Sourial, K-C Lu, E-J Hsueh
}

\author{
Division of \\ Haematology and \\ Oncology, \\ Department of \\ Medicine, Tri-Service \\ General Hospital, \\ National Defense \\ Medical Centre, \\ 8 Ting-Chow Road, \\ Number 8, Section 3 , \\ Taipei, Taiwan \\ S-H Lin \\ K-C Lu \\ E-J Hsueh \\ Department of \\ Haematology, St \\ Bartholomew's \\ Hospital, London \\ N A Sourial \\ Correspondence to: \\ Dr Shih-Hua Lin \\ Accepted for publication \\ 24 March 1994
}

\begin{abstract}
Two brothers in a Chinese family with selective malabsorption of vitamin $B_{12}$ associated with proteinuria (ImerslundGrasbeck syndrome) presented with widespread mottled skin pigmentation, termed poikiloderma. In contrast to anaemia, this pigmentary disturbance remained unresponsive to vitamin $B_{12}$ replacement. This is different from the reported hyperpigmentation sometimes seen in vitamin $B_{12}$ deficiency which is reversible following treatment. As far as is known, an irreversible and persistent skin disorder has not been reported in this syndrome before.
\end{abstract}

\section{(F Clin Pathol 1994;47:956-958)}

Familial selective malabsorption of vitamin $B_{12}$ associated with proteinuria was first described by Imerslund (1960) ${ }^{1}$ and Grasbeck et al $(1960)^{2}$ (Imerslund-Grasbeck syndrome). It is inherited as an autosomal recessive trait and is prevalent among small inbred communities such as the Lapps in Scandinavia and North African Jews. ${ }^{3}$ Only a few cases had been reported in Orientals. ${ }^{4} \mathrm{We}$ have seen two young men in a Chinese family with this syndrome associated with a skin disorder, known as poikiloderma. The anaemia in both patients responded to vitamin $B_{12}$ treatment but the skin lesions did 
not. The refractoriness of the skin lesions to vitamin $B_{12}$ treatment has not been reported before.

\section{Case reports}

A 21 year old Chinese man was admitted because of proneness to fatigue and dyspnoea on exertion, and for evaluation of a skin disorder. The latter was initially noted at the age of 4 years and was characterised as a generalised symptomless pigmentation. At the age of 5 , he sought medical attention because of dizziness and fainting spells and was found to have megaloblastic anaemia. Routine blood picture showed haemoglobin of $51 \mathrm{~g} / 1$, mean corpuscular volume (MCV) of $121 \mathrm{fl}$, leucocyte count of $2.8 \times 10^{9} / 1$, and a platelet count of $122 \times 10^{9} / 1$. He improved with cyanocobalamin $1000 \mu \mathrm{g}$ monthly given intramuscularly and has continued this treatment since then. However, the skin disorder remained. His dietary history was normal. Both parents, who are not consanguineous, and his two sisters

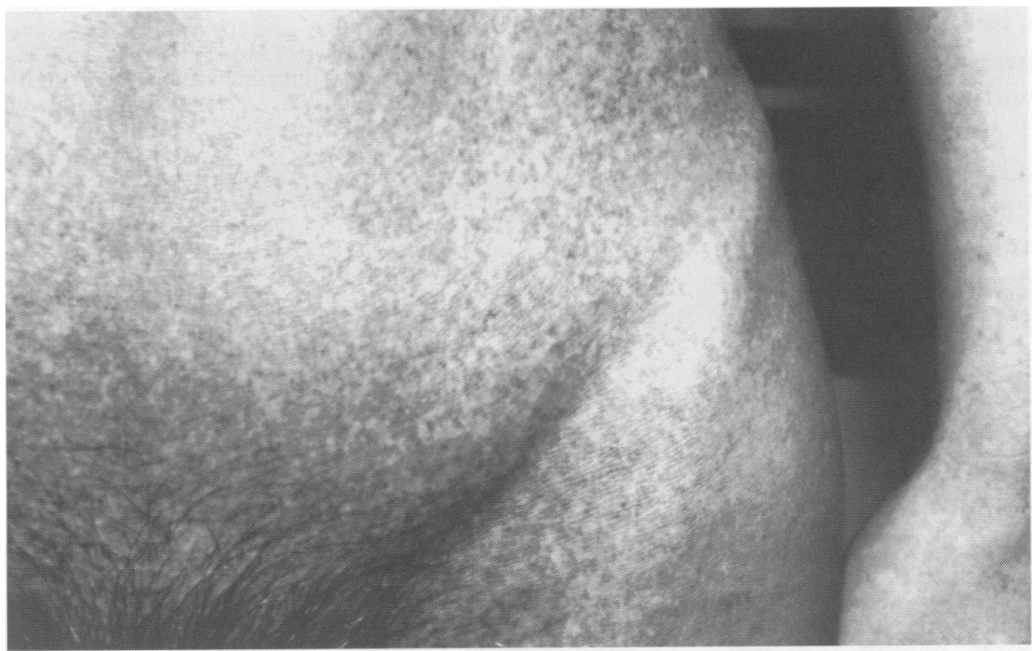

Figure 1 Poikiloderma with widespread mottled pigmentation, particularly in the region of abdomen and both groins, cannot be reversed as a result of vitamin $B_{12}$ replacement.

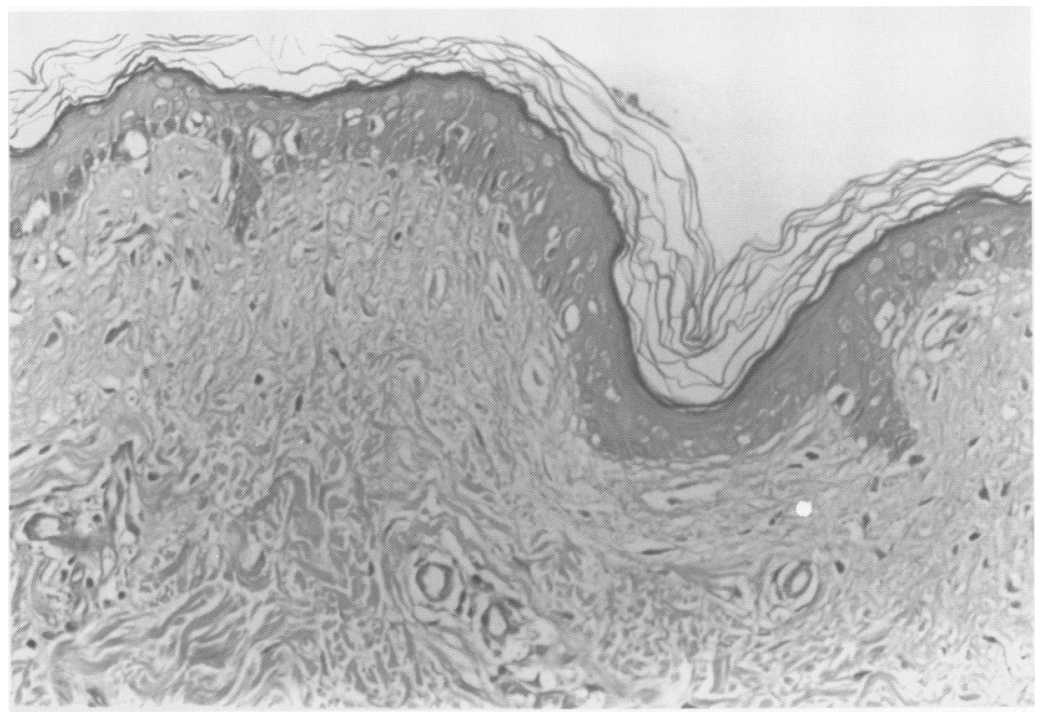

Figure 2 Hyperpigmentation after treatment, showing flattened epidermis with moderate thinning of the stratum malpighii and hydropic degeneration of basal cells associated with pigmentary incontinence (Haematoxylin and eosin).
Haematological investigations in two brothers after discontinuation of vitamin $B_{12}$ replacement for two months

\begin{tabular}{|c|c|c|}
\hline Variables (normal ranges) & Case 1 & Case 2 \\
\hline Haemoglobin $(\mathrm{g} / \mathrm{l})$ & 135 & 142 \\
\hline $\operatorname{MCV}(80-100 \mathrm{fl})$ & 96 & 94 \\
\hline White cells $\left(\times 10^{9} / 1\right)$ & $4 \cdot 4$ & $9 \cdot 9$ \\
\hline Reticulocyte count (\%) & $0 \cdot 3$ & 0.4 \\
\hline$B_{12}(150-560 \mathrm{ng} / \mathrm{l})$ & 223 & 178 \\
\hline Serum folate $(7-36 \mathrm{nmol} / \mathrm{l})$ & $8 \cdot 7$ & $7 \cdot 6$ \\
\hline Ferritin $(20-210 \mu \mathrm{g} / 1)$ & 178 & 145 \\
\hline Dicopac vitamin $\mathbf{B}_{12}$ test & & \\
\hline${ }^{57}$ Co excretion (14-40\%) & $0 \cdot 83$ & $0 \cdot 14$ \\
\hline${ }^{58}$ Co excretion (14-40\%) & $6 \cdot 23$ & $0 \cdot 40$ \\
\hline${ }^{57} \mathrm{Co:}{ }^{58}$ Co ratio $(0 \cdot 7-1 \cdot 2)$ & 0.13 & 0.35 \\
\hline Parietal cell antibody & - & - \\
\hline Serum intrinsic factor antibody & - & - \\
\hline $\begin{array}{l}\text { Gastric juice intrinsic factor antibody } \\
(14-147 \mu \mathrm{g} / 1)\end{array}$ & 70 & 20 \\
\hline$B_{12}$ unsaturated binding & 2517 & 1398 \\
\hline Transcobalamin & & \\
\hline $\begin{array}{l}\text { I and III }(235-465 \mathrm{ng} / \mathrm{l}) \\
\text { II }(680-960 \mathrm{ng} / \mathrm{l})\end{array}$ & $\begin{array}{r}887 \\
1630\end{array}$ & $\begin{array}{l}808 \\
590\end{array}$ \\
\hline $\begin{array}{l}24 \text { hour urinary protein } \\
(0.05-0.15 \mathrm{~g} / \text { day })\end{array}$ & 0.65 & 0.85 \\
\hline
\end{tabular}

appear normal and have no anaemia. His younger brother (case 2) had megaloblastic anaemia as a result of vitamin $B_{12}$ deficiency and similar skin lesions.

On admission, the patient appeared to be a well developed and well nourished man. Clubbing, koilonychia, organomegaly, and neurological deficits were absent. The results of a xylose tolerance test and biopsy specimens of stomach and small intestine were normal. Cytogenetic studies were normal. Cortisol concentrations were within normal ranges. Other studies, including a dual isotope (Dicopac) vitamin $\mathbf{B}_{12}$ absorption test, and pentagastrin test taken two months after discontinuing vitamin $B_{12}$ replacement, are shown in the table. His skin lesions presented as widespread mottled pigmentation over the whole body, especially over both groins (fig 1), back, neck, and both flanks. These lesions were exaggerated by exposure to the sun and were identified as poikiloderma. The skin biopsy specimen showed flattened epidermis, hydropic degeneration of basal cells, and pigmentary incontinence (fig 2).

The 19 year old younger brother presented with a similar clinical course. Skin manifestations appeared when he was 3 years old and megaloblastic anaemia was noted a year later. His original blood count showed a haemoglobin of $63 \mathrm{~g} / \mathrm{l}$, an $\mathrm{MCV}$ of $114 \mathrm{fl}$, a leucocyte count of $4.5 \times 10^{9} / 1$, and a platelet count of $141 \times 10^{\%} / 1$. Despite regular intramuscular cyanocobalamin treatment, the skin lesions remain unchanged. His haematological investigations (table) were also taken two months after discontinuing vitamin $\mathbf{B}_{12}$ replacement.

\section{Discussion}

The diagnosis of Imerslund-Grasbeck syndrome in our patients was confirmed by isolated vitamin $\mathrm{B}_{12}$ deficiency; malabsorption of vitamin $B_{12}$ as demonstrated by a dual isotope vitamin $B_{12}$ absorption test; intact intrinsic factor and gastric secretion; absent intrinsic factor antibody in serum; normal serum transcobalamin I, II, and III; no morphologically identifiable lesion in the stomach and 
small intestine; and persistent proteinuria with normal renal function.

The pathogenesis of vitamin $B_{12}$ malabsorption in this syndrome remains unknown. In one study, the uptake of IF-B B $_{12}$ complex in vitro by homogenised ileal biopsy specimens from one patient was found to be normal and it was therefore postulated that the defect lay at a later stage after the attachment of the IF-B ${ }_{12}$ complex to the surface of the ileal cell. ${ }^{5}$ In another detailed study of two brothers with the syndrome, IF- $B_{12}$ uptake in the ileum in vivo was examined by subcellular fractionation of ileal biopsy specimens. ${ }^{6}$ No uptake of vitamin $B_{12}$ was detected in the ileal tissue.

Reversible cutaneous pigmentation sometimes occurs in vitamin $B_{12}$ deficiency. In 1963 Baker et al described hyperpigmentation as a sign of vitamin $B_{12}$ deficiency, ${ }^{7}$ and noted its frequency in dark-skinned peoples. Indeed, almost all reports of this association have involved people from Africa or India. The importance of the association between hyperpigmentation and vitamin $B_{12}$ deficiency rests in its reversibility with vitamin $B_{12}$ replacement. The mechanism for this reversible change is unclear. It has been postulated that vitamin $\mathbf{B}_{12}$ deficiency lowers the intracellular reduction potential, with a concomitant decrease in the reduced glutathione:oxidised glutathione (GSH:GSSG) ratio. ${ }^{8}$ Once the tyrosinase inhibiting effect of GSH has been diminished, the epidermal melanocytes are then stimulated to produce melanin. At the same time, the lowered GSH concentration results in retardation of mitosis, as well as diminished DNA synthesis. This could result in epidermal atrophy and hyperpigmentation. The exaggeration of hyperpigmentation by exposure to sunlight in vitamin $\mathbf{B}_{12}$ deficiency, as observed in our patients, may be due to a further lowering of intracellular GSH content by ultraviolet light. ${ }^{9}$

In vitamin $B_{12}$ deficiency, brown skin pigmentation usually occurs over the dorsal aspects of fingers and toes, around the nails, and also on the finger pulp. These dermatological signs usually disappear after treatment. In our patients the skin manifestation was widespread mottled hyperpigmentation, especially over both groins, lateral abdomen and neck, termed poikiloderma. This peculiar pigmentary disturbance is similar to that of the patients with this syndrome described by Gillian $e t a l^{8}$ and Watson-Williams et $a .^{10}$ Of interest, was the persistence of the skin lesions in our patients, similar to the proteinuria which also persists despite vitamin $B_{12}$ treatment. The reason for this refractoriness to vitamin $B_{12}$ in our patients is unclear but may have been related to racial or genetic differences and may in part explain the heterogeneous nature of this syndrome, which may be polygenic in origin.

We thank Dr John D Kirby for reviewing the clinical photographs and Dr Lung $\mathrm{T}$ Yam for his critique of our manuscript.

1 Imerslund O. Idiopathic chronic megaloblastic anaemia in children. Acta Paediatr Scand 1960;119:1-115.

2 Grasbeck R, Gordin R, Kantero I, Kuhlback B. Selective vitamin $B_{12}$ malabsorption and proteinuria in young

3 Broch $H$, Imerslund $O$, Monn E, Hovig T, Seip $M$ Imerslund-Grasbeck anaemia. A long-term follow-up study. Acta Paediatr Scand 1984;73:248-53.

4 Liang DC, Hsu HC, Huang FY. Imerslund-Grasbeck syndrome in two brothers: Renal biopsy and ultrastructural findings. Pediatr Hematol Oncol 1991;8:361-5.

5 Mckenzie II, Donaldson RM, Trier JS, Mathan VI. Ilea mucosa in familial selective vitamin $\mathbf{B}_{12}$ malabsorption. N Engl f Med 1972;286:1021-5.

6 Burman JF, Jenkin WJ, Walker-Smith JA, Phillips AD, Sourial NA, Williams CB, et al. Absent ileal uptake of IF-bound vitamin $B_{12}$ in vivo in the Imerslund-Grasbeck syndrome (familial vitamin $B_{12}$ malabsorption with proteinuria). Gut 1985;26:311-4.

7 Baker SJ, Ignatius M, Johnson S, Vaish SK. Hyperpigmentation of the skin: a sign of vitamin $B_{12}$ defipigmentation of the skin: a sign
ciency. $B r M e d ~$
1963;i:1713-5.

8 Gillian JN, Cox AJ. Epidermal changes in vitamin $B_{12}$ deficiency. Arch Dermatol 1973;107:231-6.

9 Wiskemann A. Effects of ultraviolet light on the skins in Swanson CP, ed. Introduction to photobiology. New York Prentice-Hall Inc, 1969:81-98.

10 Watson-Williams EJ, Fleming AF. Isolated malabsorption of vitamin $B_{12}$ deficiency causing megaloblastic anaemia and hyperpigmentation in a Nigerian. Blood 1966;28: $770-5$. 